Check for updates

Cite this: RSC Adv., 2020, 10, 19562

\title{
Computational understanding of catalyst- controlled borylation of fluoroarenes: directed vs. undirected pathway $\dagger$
}

\begin{abstract}
Yu-hua Liu (D) a and Zhong-Jie Jiang (D)*b
In this work, density functional theory (DFT) calculations are performed to understand the origin of the regioselective $\mathrm{C}-\mathrm{H}$ borylation of aromatics catalyzed by $\mathrm{Co}(\mathrm{I}) /{ }^{\mathrm{iPr}} \mathrm{PNP}$ and $\operatorname{Ir}\left({ }_{11}\right) / \mathrm{dtbpy}(4,4$-di-tert-butyl bipyridine). The calculation results indicate that for the $\mathrm{Co}_{(1)} /{ }^{\mathrm{iPr}} \mathrm{PNP}$ catalytic system, the undirected pathway is $2.9 \mathrm{kcal} \mathrm{mol}^{-1}$ more favoured over the directed pathway leading to ortho-to-fluorine selectivity. In contrast, for the $\mathrm{Ir}(\mathrm{III}) / \mathrm{dtbpy}$ catalytic system, the directed pathway is $1.2 \mathrm{kcal} \mathrm{mol}^{-1}$ more favoured over the undirected pathway bringing about ortho-to-silyl selectivity. For Co(I)/PrPNP catalyzed borylation, the undirected pathway which involves steps of ortho-to-fluorine $\mathrm{C}-\mathrm{H}$ oxidative addition, $\mathrm{C}-\mathrm{B}$ reductive elimination, $\mathrm{B}-\mathrm{B}$ oxidative addition, and $\mathrm{B}-\mathrm{H}$ reductive elimination is favorable due to the electron deficient character of the ortho-to-fluorine $\mathrm{C}-\mathrm{H}$ bond. For $\operatorname{Ir}(\mathrm{III}) / \mathrm{dtbpy}$ catalyzed borylation, the directed pathway consisting of $\mathrm{Si}-\mathrm{H}$ oxidative addition, $\mathrm{B}-\mathrm{H}$ reductive elimination, $\mathrm{C}-\mathrm{H}$ oxidative addition, $\mathrm{B}-\mathrm{B}$ oxidative addition, $\mathrm{C}-\mathrm{B}$ reductive elimination, $\mathrm{Si}-\mathrm{H}$ reductive elimination is favored over the undirected pathway attributed to the directing effect of the hydrosilyl group. The favourable undirected pathway (ortho-to-fluorine selectivity) for Co(1)/PrPNP catalyzed borylation and the favourable directed pathway (ortho-to-silyl selectivity) for $\operatorname{Ir}($ III)/dtbpy catalyzed borylation could explain well the experimentally observed ortho-to-fluorine borylation of hydrosilyl substituted fluoroarenes with cobalt catalyst (J. V. Obligacion, M. J. Bezdek and P. J. Chirik, J. Am. Chem. Soc., 2017, 139, 2825-2832) and ortho-to-silyl selectivity with iridium catalyst (T. A. Boebel and J. F. Hartwig, J. Am. Chem. Soc.,

2008, 130, 7534-7535).
\end{abstract}

Received 17th April 2020

Accepted 18th May 2020

DOI: $10.1039 / d 0 r a 03428 b$

rsc.li/rsc-advances

\section{Introduction}

Transition metal catalyzed $\mathrm{C}-\mathrm{H}$ borylation of aromatics has attracted considerable attention as it offers an alternative method to standard organic synthesis. ${ }^{1}$ However, different $\mathrm{C}-\mathrm{H}$ bonds in reactants can result in different functionalization, leading to the formation of the resulting products with substantially different properties. ${ }^{2}$ Therefore, controlling the regioselectivity of the $\mathrm{C}-\mathrm{H}$ borylation reaction is of great importance to obtain the desired synthetics. Generally, strategies for the regioselective $\mathrm{C}-\mathrm{H}$ borylation of aromatics include the undirected reaction pathway, in which no directing groups are involved in the reaction, ${ }^{3}$ and directing group controlled regioselective borylation, ${ }^{3 f-j}$ where the reaction regioselectivity is well controlled by a directing group.

${ }^{a}$ School of Physics and Electronic Engineering, Guangzhou University, Guangzhou, 510006, China

${ }^{b}$ Guangzhou Key Laboratory for Surface Chemistry of Energy Materials, New Energy Research Institute, College of Environment and Energy, South China University of Technology, Guangzhou 510006, Guangdong, China. E-mail: eszjiang@scut.edu.cn

$\dagger$ Electronic supplementary information (ESI) available. See DOI: $10.1039 /$ d0ra03428b
Hartwig reported that the ortho-to-fluorine selectivity was controlled by steric hindrance in iridium/dtbpy catalyzed borylation of trisubstituted fluoroarenes ${ }^{4}$ (Scheme 1a) in which the product of borylated fluoroarene is especially essential for pharmaceutical chemistry. ${ }^{5}$ In contrast, Chatani reported platinumNHC catalyzed C-H borylation of fluoroarenes, which afforded ortho-to-fluorine arylboronates with no steric protection. ${ }^{6}$ Similarly, Iwasawa reported the ortho-to-fluorine effect in platinum/

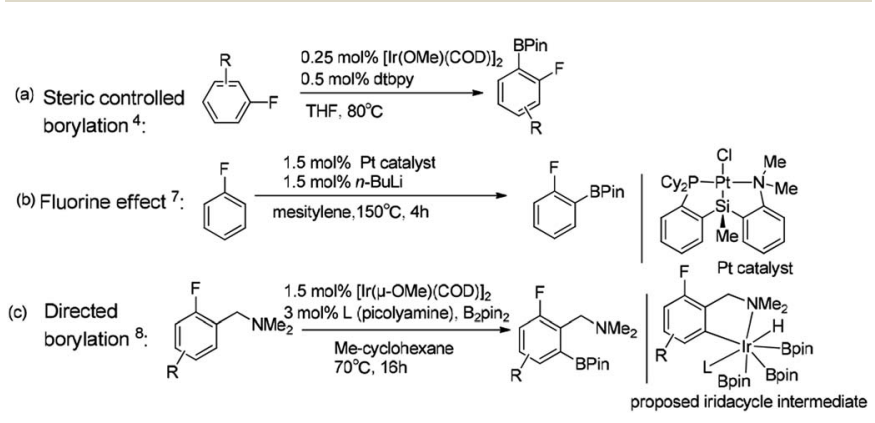

Scheme 1 Complementary selectivity in transition metal catalyzed $\mathrm{C}(\mathrm{sp} 2)-\mathrm{H}$ borylation of fluoroarenes. ${ }^{5,7,8}$ 

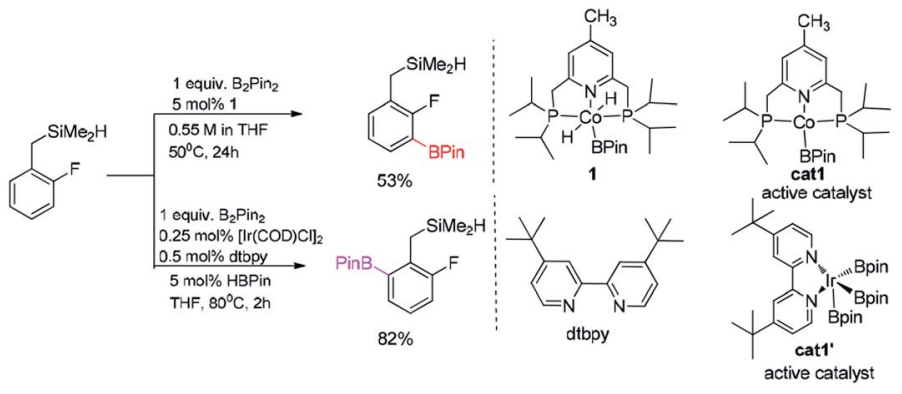

Scheme 2 Computational model for borylation of hydrosilyl substituted fluoroarenes. ${ }^{11}$

PSiN catalyzed C-H borylation of arenes $^{7}$ (Scheme 1b). Different from the steric controlled borylation by installing large group on the substrate or catalyst, introducing directing group bearing heteroatoms (e.g. $\mathrm{N}, \mathrm{O}, \mathrm{S}, \mathrm{Si}$ ) on the substrate is an effective way to achieve meta/para-to-fluorine $\mathrm{C}-\mathrm{H}$ borylation. ${ }^{8-10}$ The interactions between directing groups and catalyst could bring one of the ortho- $\mathrm{C}-\mathrm{H}$ bonds close to the metal center and promote its regioselective activation. ${ }^{9 a, b}$ For example, Iwasawa reported the iridium-picolylamine catalyzed ortho-to-amine borylation of fluoroarenes using dimethylamine as the directing group ${ }^{8}$ (Scheme 1c). Hartwig et al. reported the hydrosilyl directed borylation of fluoroarenes catalyzed by iridium/dtbpy favoring ortho-to-silyl selectivity $^{\mathbf{1 0}}$ (Scheme 2). In contrast, Obligacion et al. reported the same reaction catalyzed by cobalt $/{ }^{i \mathrm{Pr}} \mathrm{PNP}$ with ortho-tofluorine selectivity ${ }^{\mathbf{1 1}}$ (Scheme 2).

The examples mentioned above clearly demonstrate that the $\mathrm{C}-\mathrm{H}$ borylation of aromatics can proceed by the undirected or directed pathways with the iridium or cobalt-based catalysts. ${ }^{12,13}$ Recently, Hall's group had reported the cobalt pincer complex catalyzed regioselective borylation of $\operatorname{aromatics}^{13 b}$ (without directing group) while Sunoj's group reported the use of hydrosilyl $\left(-\mathrm{SiR}_{2} \mathrm{H}\right)$ as a directing group in the iridium-catalyzed regioselective borylation of the benzylic $\mathrm{C}-\mathrm{H}$ bond. ${ }^{9 a}$ Although there have been some reports on the $\mathrm{Si}-\mathrm{Co}$ and $\mathrm{Si}-\mathrm{Ir}$ metal complex, ${ }^{31,9 a, 12 d}$ and the directing effect of the silyl group has been identified in iridium catalyzed borylation of benzylic $\mathrm{C}-\mathrm{H}$ bond, ${ }^{9 a}$ detailed mechanism study on the regioselectivity of the borylation reactions in Scheme 2 has not been reported. In the iridium and cobalt catalyzed borylation of hydrosilyl substituted fluoroarenes (Scheme 2), how about directing effect of hydrosilyl group for both the cobalt and the iridium catalyzed borylation? Is the directing effect always favourable? Based on these considerations, we studied the detailed mechanism of borylation of hydrosilyl substituted fluoroarenes catalyzed by iridium and cobalt by density functional theory (DFT) method. Specifically, our attention mainly focuses on the questions raised by experimental observations: (1) what are the details of the reaction pathways? (2) which step is the rate-determining step?

\section{Results and discussion}

We choose the reaction between hydrosilyl substituted fluoroarenes and $\mathrm{B}_{2} \mathrm{pin}_{2}$ as the model (Scheme 2). Activations of both ortho-to-fluorine $\mathrm{C}-\mathrm{H}$ bond and ortho-to-silyl $\mathrm{C}-\mathrm{H}$ bond by the cobalt catalyst $\mathbf{1}$ and $\operatorname{Ir}(\mathrm{III}) / \mathrm{dtbpy}$ are calculated to make comparison and explain the regiochemical preference (Scheme 2). Since the work by Patel et al..$^{12 a}$ and Obligacion et al..$^{13}$ have suggested that the most likely active catalysts for $\mathrm{Co}(\mathrm{I})$ and $\operatorname{Ir}(\mathrm{III})$ catalyzed borylation reactions are cat1 and cat 1 , respectively, we discuss all the reaction pathways in the following sections with cat 1 and cat1 ${ }^{\prime}$ as the starting points, given that a cascade of steps along the reaction pathways is triggered by the active catalysts.

According to the probable mechanisms of $\operatorname{Ir}(\mathrm{III})$ and $\mathrm{Co}(\mathrm{I})$ catalyzed borylation of aromatics proposed in literature, ${ }^{12 a, 13}$ the directing group controlled borylation catalyzed by iridium may proceed in a way that the iridium centre is brought close to the ortho-to-silyl $\mathrm{C}-\mathrm{H}$ bond by the silyl group and induces the activation of ortho-to-silyl $\mathrm{C}-\mathrm{H}$ bond to form a 5-membered cycle. ${ }^{12 a}$ In contrast, cobalt-catalyzed borylation starts with ortho-to-fluorine $\mathrm{C}-\mathrm{H}$ oxidative addition ${ }^{\mathbf{1 3}}$ and no participation of directing group. The adaption of reported mechanisms to our peculiar reaction system is shown in Fig. 1. The proposed pathways consist of the directed and undirected pathway. For
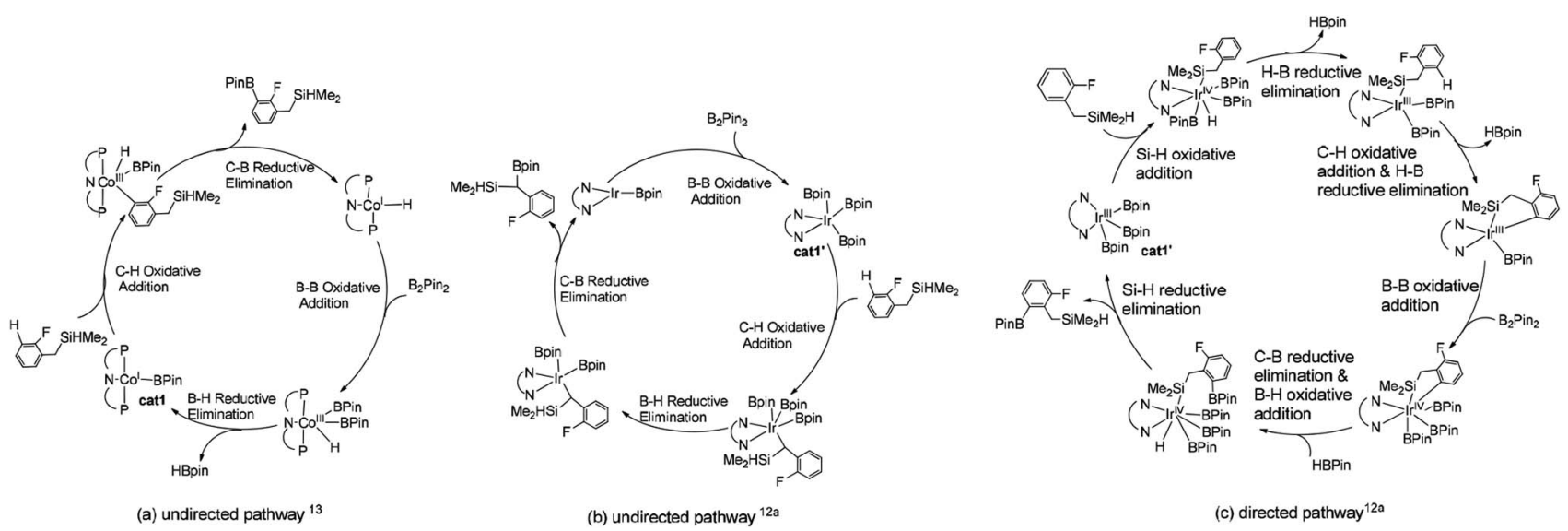

Fig. 1 Potential mechanisms of (a) directed pathway for borylation of aromatic $\mathrm{C}-\mathrm{H}$ bond ${ }^{13}$ and (b) undirected pathway for borylation of $\mathrm{Si}-\mathrm{H}$ bond $^{12 a}$ (c) directed pathway for borylation of benzylic $\mathrm{C}-\mathrm{H}$ bond. ${ }^{12 a}$ 
undirected pathway (Fig. 1a), the cobalt catalyst 1 triggers a cascade of significant steps which involves: (i) B-B oxidation addition, (ii) $\mathrm{H}-\mathrm{B}$ reductive elimination, (iii) $\mathrm{C}-\mathrm{H}$ oxidation addition, and (iv) $\mathrm{C}-\mathrm{B}$ reductive elimination. Alternatively, the undirected pathway may refer to the activation of the benzylic $\mathrm{C}-\mathrm{H}$ bond which involves (Fig. 1b): (i) $\mathrm{C}-\mathrm{H}$ oxidation addition, (ii) $\mathrm{H}-\mathrm{B}$ reductive elimination, (iii) $\mathrm{C}-\mathrm{B}$ reductive elimination, and (iv) B-B oxidation addition. While, directed pathway catalyzed by iridium is divided into six distinct steps (Fig. 1c): (i) Si$\mathrm{H}$ oxidation addition to $\mathrm{Ir}$ center; (ii) $\mathrm{H}-\mathrm{B}$ reductive elimination; (iii) $\mathrm{C}-\mathrm{H}$ bond oxidation addition \& $\mathrm{H}-\mathrm{B}$ reductive elimination; (iv) $\mathrm{B}-\mathrm{B}$ oxidation addition; (v) $\mathrm{C}-\mathrm{B}$ bond formation; (v) $\mathrm{H}-\mathrm{B}$ addition; (vi) Si-H elimination. There is also a possibility that both the directed and undirected pathways co-exist for the cobalt/iridium-catalyzed $\mathrm{C}-\mathrm{H}$ activation process. Significant differences exist between the three catalytic cycles. The preference for which pathway depends on the nature of the catalyst such as the numbers of open coordination sites on the transition metal centre of catalyst and electronic effects of the catalyst. In the following section, we use the DFT method to calculate both directed and undirected $\mathrm{C}-\mathrm{H}$ activation pathways to identify the energetically most favored pathway, with the aim of revealing the details of the mechanism.

\section{$\mathrm{Co}(\mathrm{I}) /{ }^{\mathrm{iPr}} \mathrm{PNP}$ catalyzed undirected and directed pathway}

We have examined the geometric and energy features of each elementary step involved in the $\mathrm{Co}(\mathrm{I}) /{ }^{\mathrm{iPr}} \mathrm{PNP}$ catalyzed directed and undirected pathways. The optimized structures of selected transition states (TS) and intermediates are given in Fig. 2, while the energy profiles are presented in Fig. 3. All the TS structures and $\mathrm{Co}(\mathrm{I})$ species studied show the tridentate coordination of the pincer ligand. The Co-N distance of cobalt pincer-complex cat1 (Fig. 2) is rather short, $2.00 \AA$.

The directed pathway starts from silylation (Fig. 3a, dull red). The hydrogen of hydrosilyl group approaches cobalt centre from the position adjacent to boryl group affording Int3a via TS2a with a barrier of $23.0 \mathrm{kcal} \mathrm{mol}^{-1}$ (Fig. 3a). The comparison of geometry between TS2a and cat1 indicates that $\mathrm{Si}-\mathrm{H}$ bond approaches to the axial position of the metal center, pushes the equatorial boryl ligands to the axial position (Fig. 2). ${ }^{\mathbf{1 4}}$ The distance between the incoming hydride and the boron atom Int3a is $1.34 \AA$ (Fig. 2) indicating a weak orbital interaction between the vacant $\mathrm{p}$ orbitals of the boron and the hydride..$^{15,16}$ It is expected that Int3a first converts to Int5a to release vacant coordination sites via expulsion of a molecule of HBpin. The required energy for the removal of a molecular of HBpin from Int3a is only $3.0 \mathrm{kcal} \mathrm{mol}^{-1}$. The ortho-to-silyl aromatic $\mathrm{C}-\mathrm{H}$ bond in Int5a is brought close to the cobalt center by silyl group, such that $\mathrm{C}-\mathrm{H}$ could oxidatively add to cobalt center affording Int7a via a cyclic transition state TS6a (Fig. 2). At first glance, there is a possibility that $\mathrm{B}_{2} \mathrm{pin}_{2}$ oxidatively adds to the cobalt center of Int7a. However, attempts to find a corresponding TS is failed, presumably resulting from the unavailable coordination sites on the cobalt center. Subsequently, we investigate the possibility of $\mathrm{Si}-\mathrm{H}$ bond reductive elimination from Int7a. The reductive elimination of $\mathrm{Si}-\mathrm{H}$ bond from Int7a affords Int9a via TS8a.
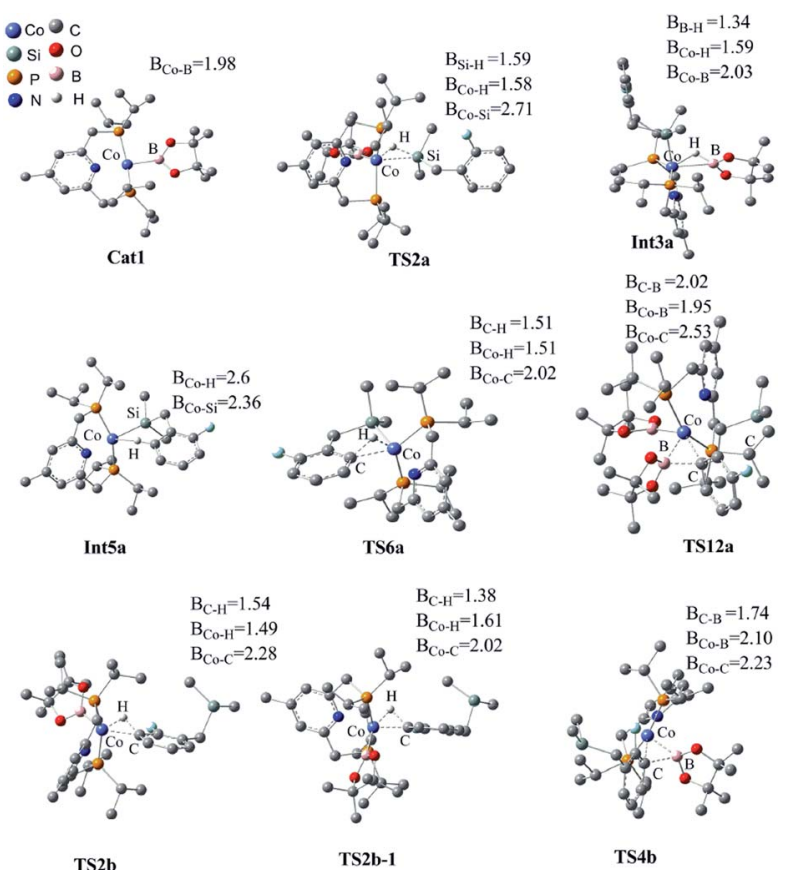

Fig. 2 Optimized structures of the key transition states and interme-

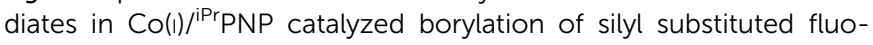
roarenes, along with the key bond distances in angstroms. Color code, $\mathrm{C}$ : dark gray, O: red, B: pink, $\mathrm{H}$ : light gray, $\mathrm{N}$ : dark blue, Co: light blue, Si: celeste, P: yellow. Irrelevant hydrogen atoms are omitted for clarity.

Given that there are partially open coordination sites at the cobalt center in Int9a, $\mathrm{B}_{2} \mathrm{pin}_{2}$ could add to the cobalt center to form Int11a. One of the boryl ligand in Int11a approaches the adjacent aromatic carbon to form C-B bond via TS12a (Fig. 2). Upon the $\mathrm{C}-\mathrm{B}$ bond reductive elimination, the product $\mathbf{p 1 a}$ is afforded, and active catalyst cat1 is regenerated. Along with the energetic profile of the directed pathway (Fig. 3, dull red), the overall barrier for the $\mathrm{C}-\mathrm{B}$ reductive elimination via $\mathrm{TS} 12 \mathrm{a}$ is the largest (43.0 $\mathrm{kcal} \mathrm{mol}^{-1}$ ), and can be considered as the rate determining step. Starting from int9a, in place of $\mathrm{B}_{2} \mathrm{Pin}_{2}$ oxidative addition, HBpin is also possible to add to the cobalt center following with the $\mathrm{C}-\mathrm{B}$ reductive elimination and regeneration of cat1. The corresponding energetic profile is shown in Fig. 3, which shows an overall barrier of $34.2 \mathrm{kcal} \mathrm{mol}^{-1}$ (TS12a-1 in Fig. 3b). It is noteworthy that in this path the steps of the catalyst regeneration is the same as that in undirected path II (Fig. 3a, Int5b $\rightarrow$ cat1) and the steps before Int9a are the same as those in the directed path I (Fig. 3a, cat1 $\rightarrow$ Int9a).

Different from the directed pathway, the undirected pathway starts with the ortho-to-fluorine $\mathrm{C}-\mathrm{H}$ activation. In this step, the ortho-to-fluorine hydrogen may approach cobalt center from the position adjacent to boryl group or from the location opposite to the boryl group to afford $\mathbf{T S} 2 \mathbf{b}-\mathbf{1}$ and $\mathbf{T S} 2 \mathbf{b}$ which requires an energy of $31.6 \mathrm{kcal} \mathrm{mol}^{-1}$ and $27.5 \mathrm{kcal} \mathrm{mol}^{-1}$, respectively. For the former approach, the carbon and boryl group is in an opposite position which is impossible for the subsequent $\mathrm{C}-\mathrm{B}$ reductive elimination to afford the borylated product. So, we do not calculate the pathway along with the former. The intermediate Int3b is obtained via TS2b. The incoming hydride and 

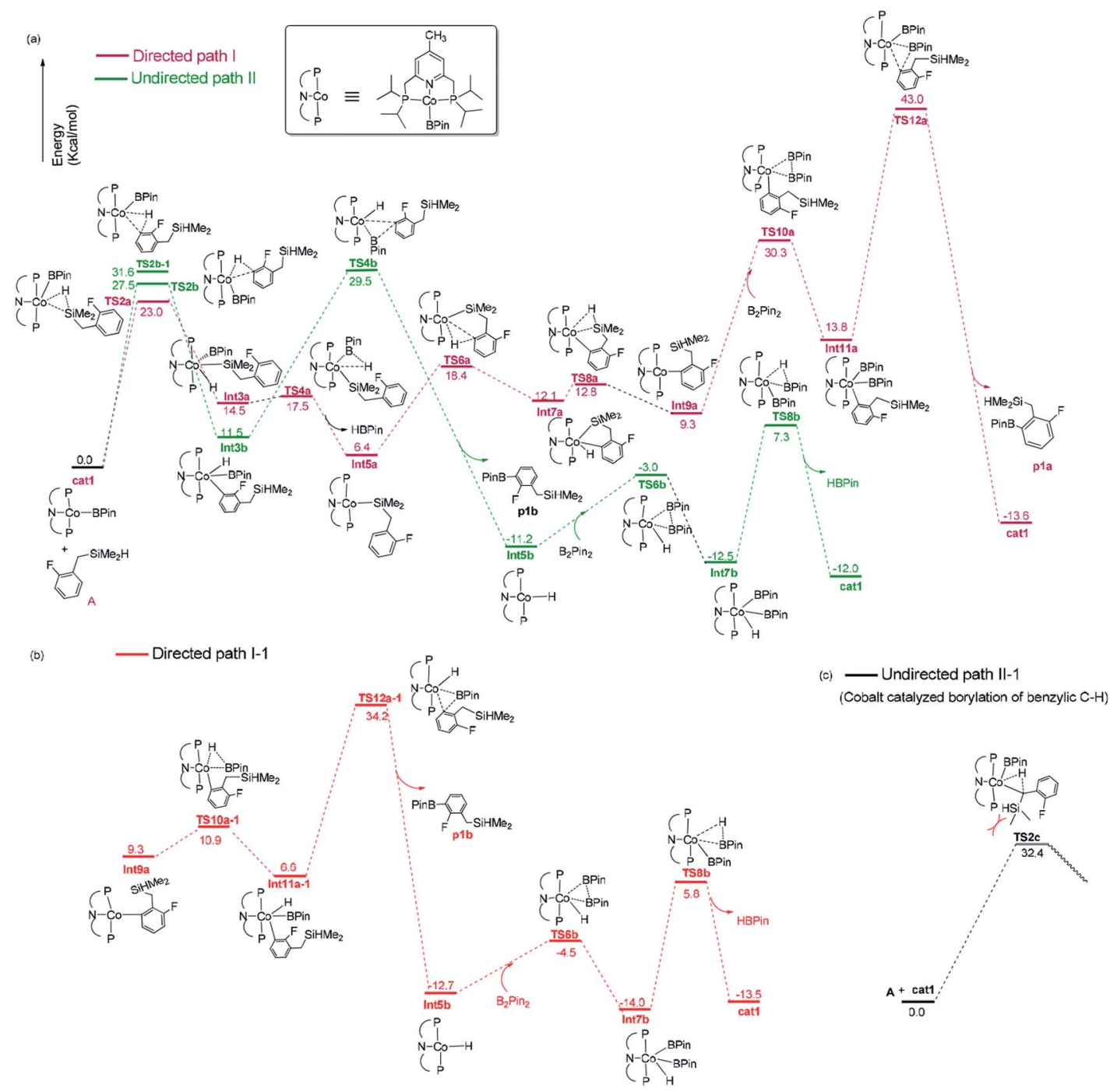

Fig. 3 Gibbs free energy profile of directed path I and path I-1, undirected path II and path II-1 in the borylation of hydrosilyl substituted fluoroarenes catalyzed by $\mathrm{Co}(\mathrm{I}) /{ }^{\mathrm{iPr}} \mathrm{PNP}$.

boryl group of Int $3 \mathbf{b}$ are situated in the equatorial position (Fig. 2). Then, the aromatic C-B is reductively eliminated from Int3b via TS4b, affording the product $\mathbf{p} \mathbf{1 b}$. The overall barrier for the C-B reductive elimination is the largest $\left(29.5 \mathrm{kcal} \mathrm{mol}^{-1}\right)$ and is the rate-determining step (Fig. 3a). The catalyst cat1 is regenerated upon the following $\mathrm{B}-\mathrm{B}$ oxidative addition and $\mathrm{B}-\mathrm{H}$ reductive elimination, which require an energy of $8.2 \mathrm{kcal} \mathrm{mol}^{-1}$ and $19.8 \mathrm{kcal} \mathrm{mol}^{-1}$, respectively. In addition, we have calculated the pathway for $\mathrm{Co}(\mathrm{I})$-catalyzed benzylic $\mathrm{C}-\mathrm{H}$ borylation (Fig. 3c). As a result of the steric hindrance between the ligand and the silyl group, the barrier for the benzylic $\mathrm{C}-\mathrm{H}$ activation (32.4 $\mathrm{kcal} \mathrm{mol}^{-1}$ ) is too high to occur under the experimental condition $\left(50^{\circ} \mathrm{C}, 24 \mathrm{~h}\right)$. This calculation result is different from the hydrosilyl directed borylation of ortho-hydrosilyl benzene in which the borylation of the benzylic $\mathrm{C}-\mathrm{H}$ is favorable over the aromatic $\mathrm{C}-\mathrm{H}$ bond activation..$^{9 a}$

Obviously, the overall barrier in the undirect pathway (29.5 kcal mol ${ }^{-1}$, TS4b in Fig. 3a) for $\mathrm{Co}(\mathrm{I}) f^{j \mathrm{Pr}} \mathrm{PNP}$ system is much lower than that of the direct pathway $\left(43.0 \mathrm{kcal} \mathrm{mol}^{-1}\right.$ barrier for TS12a in Fig. 3a or $34.2 \mathrm{kcal} \mathrm{mol}^{-1}$ barrier for TS12a1 in Fig. 3b) We believe that the lower overall barrier of the undirected pathway than directed pathway can be ascribed to the electron-withdrawing of the fluorine atom ortho to the activated $\mathrm{C}-\mathrm{H}$ bond, because the electron deficiency property of the transition state accelerates the $\mathrm{C}-\mathrm{B}$ reductive elimination (18.0 kcal mol ${ }^{-1}$ of the barrier for TS4b vs. $29.2 \mathrm{kcal} \mathrm{mol}^{-1}$ of that for TS4a, Fig. 3a). Such a high barrier difference between the directed and undirected pathway $\left(29.5 \mathrm{kcal} \mathrm{mol}^{-1}\right.$ overall barrier for TS4b in the undirected pathway vs. $43.0 \mathrm{kcal} \mathrm{mol}^{-1}$ barrier for TS12a or $34.2 \mathrm{kcal} \mathrm{mol}^{-1}$ barrier for TS12a-1 in the directed pathway, Fig. 3) suggests that the $\mathrm{Co}(\mathrm{I}) /{ }^{\mathrm{iPr}} \mathrm{PNP}$ catalyzed borylation favors the undirect pathway. With $\mathrm{Co}(\mathrm{I}) /{ }^{\mathrm{iPr}} \mathrm{PNP}$ catalytic system, the calculated favorable undirect pathway (orthoto-fluorine selectivity) is well consistent with the experimental observed ortho-to-fluorine regioselectivity which is reported in the literature ${ }^{11}$ (53\%, Scheme 2), strongly suggesting the accuracy of our calculation. Additionally, the slightly high barrier of undirected pathway $\left(29.5 \mathrm{kcal} \mathrm{mol}^{-1}\right)$ also well explains the 

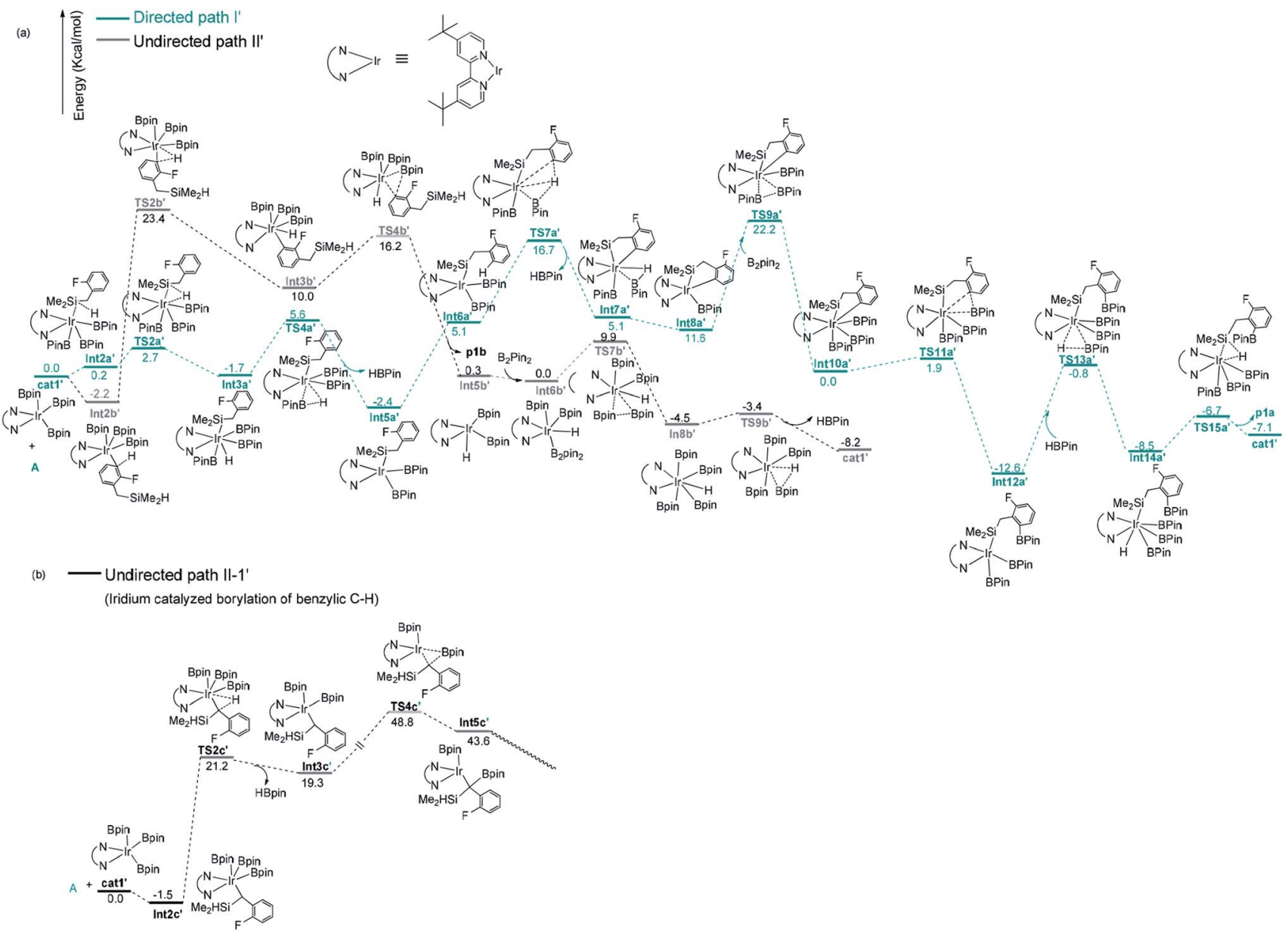

Fig. 4 Gibbs free energy profile of path $\mathrm{I}^{\prime}$ and path $\mathrm{II}^{\prime}$ in borylation of silyl substituted fluoroarenes with Ir(III)/dtbpy system.

relatively low chemical yield in the cobalt catalyzed model reaction $(53 \%) .{ }^{12}$ It is worth noting that a recent computational study has revealed that the cobalt-carbon bonds of the intermediate in the ( $\left.{ }^{\mathrm{iPr}} \mathrm{PNP}\right) \mathrm{Co}$-catalyzed borylation could be strengthened by the ortho-fluorine atom, which gives an additional demonstration of the ortho-to-fluorine regioselectivity other than para- or meta-selectivity. ${ }^{13 g}$

\section{Ir(III) catalyzed undirected and directed pathway}

After a brief study on the directed and undirected pathways catalyzed by $\mathrm{Co}(\mathrm{I}) /{ }^{\mathrm{iPr}} \mathrm{PNP}$, we turn to the similar pathways catalyzed by $\operatorname{Ir}(\mathrm{III}) / \mathrm{dtb} y$ catalytic system. The energy and geometric features of each elementary step involved in the $\operatorname{Ir}(\mathrm{III}) /$ dtbpy catalyzed directed and undirected pathways are shown in Fig. 4 and 5.

For the undirected path $\mathrm{I}^{\prime}$, the catalytic cycle starts with ortho-to-fluorine $\mathrm{C}-\mathrm{H}$ activation of the substrate $\mathbf{A}$ to form Int3 $\mathbf{b}^{\prime}$ via $\mathbf{T S} 2 \mathbf{b}^{\prime}$ (a barrier of $25.6 \mathrm{kcal} \mathrm{mol}^{-1}$, Fig. 4a). The energy required for the subsequent $\mathrm{C}-\mathrm{B}$ reductive elimination is $6.2 \mathrm{kcal} \mathrm{mol}^{-1}$ (TS4b', Fig. 4a). After C-B reductive elimination, the intermediate Int6 $\mathbf{b}^{\prime}$ is formed and coordinates with $\mathrm{B}_{2} \mathrm{pin}_{2}$ via $\mathbf{T S} 7 \mathbf{b}^{\prime}$, which requires an energy of $9.9 \mathrm{kcal} \mathrm{mol}^{-1}$, a molecular HBpin is released via $\mathbf{T S 9 b}^{\prime}$, which require an energy of $1.1 \mathrm{kcal} \mathrm{mol}^{-1}$, and finally, the catalytic cycle is closed by the regeneration of the catalyst cat1' ${ }^{\prime}$. The most stable intermediate in undirected path $I^{\prime}$ is Int2 $\mathbf{b}^{\prime}$. The intermediate Int5a' in the directed path $\mathrm{II}^{\prime}$ is $0.2 \mathrm{kcal} \mathrm{mol}^{-1}$ more stable than Int $2 \mathbf{b}^{\prime}$, and the "population" of Int $2 \mathbf{b}^{\prime}$ will be marginally smaller than the population of Int5a'. The reaction may proceed from the intermediate Int5a'. Therefore, in a strict sense, the overall energy barrier within $\mathrm{C}-\mathrm{H}$ approximation should be calculated as the energy difference between $\mathbf{T S} 2 \mathbf{b}^{\prime}$ and Int5a' $\left(25.8 \mathrm{kcal} \mathrm{mol}^{-1}\right.$, Fig. 4a).

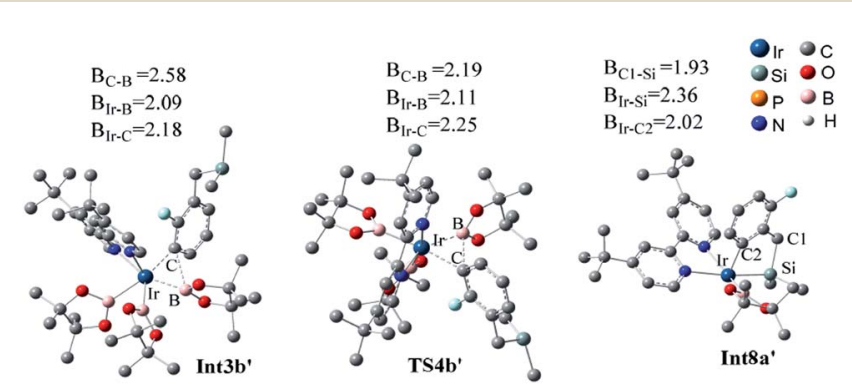

Fig. 5 Optimized structures of the key transition states and intermediates in Co(1)/iPrPNP catalyzed borylation of silyl substituted fluoroarenes, along with the key bond distances in angstroms. color code, $\mathrm{C}$ : dark gray, O: red, B: pink, H: light gray N: dark blue, Co: light blue, Si: celeste, P: yellow. Irrelevant hydrogen atoms are omitted for clarity. 
It is worth noting that the barrier for the initial ortho-tofluorine $\mathrm{C}-\mathrm{H}$ activation catalyzed by $\operatorname{Ir}(\mathrm{III}) / \mathrm{dtbpy}$ is lower than that catalyzed by $\mathrm{Co}(\mathrm{I}) j^{j \mathrm{Pr}} \mathrm{PNP} \quad\left(25.8 \quad \mathrm{kcal} \quad \mathrm{mol}^{-1} v s\right.$. $27.5 \mathrm{kcal} \mathrm{mol}^{-1}$ ) (TS2 $\mathbf{b}^{\prime}$ in Fig. 4a vs. TS2b in Fig. 3a), which can be ascribed to the electron effects on the transition states of $\mathrm{C}-\mathrm{H}$ activation. Comparing the transition states of the ortho-tofluorine $\mathrm{C}-\mathrm{H}$ activation in cobalt and iridium catalyzed borylation (TS2b, TS2 $\mathbf{b}^{\prime}$ ), the Mulliken charge on the cobalt center of TS2b is negative while that on iridium of TS2 $\mathbf{b}^{\prime}$ is positive $(-0.517325$ vs. 0.349631 , Fig. 1, ESI $\dagger)$, which shows stronger electron withdrawing effect of iridium center than that of cobalt center. We propose that the electron withdrawing character of iridium center could facilitate the ortho-to-fluorine $\mathrm{C}-\mathrm{H}$ activation, which may explain for the lower barrier of TS2 $\mathbf{b}^{\prime}$ (Fig. 4a) than that of TS2b (Fig. 3a) (25.8 kcal mol ${ }^{-1} v s .27 .5 \mathrm{kcal} \mathrm{mol}^{-1}$ ).

Additionally, as for iridium catalyzed directed path $\mathrm{I}^{\prime}$, the active catalyst cat1 ${ }^{\prime}$ triggers the catalytic cycle by silylation, which only requires an energy of $2.7 \mathrm{kcal} \mathrm{mol}^{-1}$ (TS2a'). Given that the formed Int $3 \mathrm{a}^{\prime}$ is saturated coordination, ${ }^{13 a}$ it is expected to exclude one molecular of HBpin prior to the $\mathrm{C}-\mathrm{H}$ oxidative insertion. Upon release of one molecular HBpin, the following $\mathrm{C}-\mathrm{H}$ oxidative insertion is accompanied by the release of another molecular HBpin which can be confirmed by IRC calculations. Then the intermediate Int8a' is afforded, which has open coordination sites. One equivalent of $\mathrm{B}_{2} \operatorname{pin}_{2}$ thereafter oxidatively add to Int8a', generating Int10a' via TS9a', with an overall barrier of $24.6 \mathrm{kcal} \mathrm{mol}^{-1}$. In the intermediate Int10a', one boryl group is situated close to the ortho-to-silyl aromatic carbon (Fig. 4a). Then, C-B bond is formed via $\mathrm{C}-\mathrm{B}$ reductive elimination from Int10a', affording Int12a' via $\mathbf{T S}^{\prime} 1 \mathbf{a}^{\prime}$. Because intermediate Int12a' has open coordination sites, one molecular HBpin is added to iridium center of Int12a' to generate Int14a' via TS13a'. The added HBpin provides hydrogen for the subsequent reductive elimination of the $\mathrm{Si}-\mathrm{H}$ bond. Upon $\mathrm{Si}-\mathrm{H}$ reductive elimination, the catalytic cycle is closed by affording the final product and regeneration of catalyst cat1'.

In addition, we have calculated the pathway for Ir-catalyzed benzylic C-H borylation (Fig. 4b). The barrier for path $\mathrm{II}-\mathrm{1}^{\prime}$ is much higher $\left(48.8 \mathrm{kcal} \mathrm{mol}^{-1}\right)$ than other pathways $\left(25.8 \mathrm{kcal} \mathrm{mol}^{-1}\right.$ for Ir catalyzed undirected path II'; $24.6 \mathrm{kcal} \mathrm{mol}^{-1}$ for Ir catalyzed directed path I') and should be finally ruled out. Similar to Co(I)-catalyzed benzylic C-H borylation, it is different from the hydrosilyl directed borylation of ortho-hydrosilyl benzene in which the borylation of the benzylic $\mathrm{C}-\mathrm{H}$ bond is favorable over the borylation of the aromatic $\mathrm{C}-\mathrm{H}$ bond..$^{9 a}$ Comparing the rate-determining step in the directed path $\mathrm{I}^{\prime}$ and undirected path $\mathrm{II}^{\prime}$ for the iridium catalyzed $\mathrm{C}-\mathrm{H}$ borylation (TS9a' vs. TS2 $\mathbf{b}^{\prime}$ ), the directed pathway leading to ortho-to-silyl selectivity is $1.2 \mathrm{kcal} \mathrm{mol}^{-1}$ more favorable over undirected pathway leading to ortho-to-fluorine selectivity (24.6 kcal mol ${ }^{-1}$ barrier of TS9a' in Fig. 4 a vs. $25.8 \mathrm{kcal} \mathrm{mol}^{-1}$ barrier of TS2 $\mathbf{b}^{\prime}$ in Fig. 4a).With $\operatorname{Ir}($ III)/dtbpy catalytic system, the calculated favorable directed pathway (ortho-to-silyl selectivity) is also consistent with experimental observed ortho-to-silyl selectivity ${ }^{11}$ (82\%, Scheme 2).

\section{Conclusions}

The mechanisms of regioselective borylation of hydrosilyl substituted fluoroarenes by $\operatorname{Ir}(\mathrm{III}) / \mathrm{dtbpy}$ and $\mathrm{Co}(\mathrm{I}) /^{/ \mathrm{Pr}} \mathrm{PNP}$ catalysts have been studied by DFT calculation. It shows that the borylation of hydrosilyl substituted fluoroarenes by $\operatorname{Ir}($ III)/dtbpy exhibits an ortho-to-hydrosilyl selectivity and follows a directed reaction pathway consisting of steps: (i) $\mathrm{Si}-\mathrm{H}$ oxidative addition (ii) $\mathrm{H}-\mathrm{B}$ reductive elimination, (iii) $\mathrm{C}-\mathrm{H}$ bond oxidative addition and $\mathrm{H}-\mathrm{B}$ reductive elimination, (iv) B-B oxidative addition, (v) C-B formation, (vi) $\mathrm{H}-\mathrm{B}$ oxidative addition and (vi) $\mathrm{Si}-\mathrm{H}$ reductive elimination. The preference for ortho-to-hydrosilyl selectivity in $\operatorname{Ir}($ III)/dtbpy catalyzed borylation can be attributed to the directing effect of hydrosilyl group. The borylation of hydrosilyl substituted fluoroarenes by $\operatorname{Co}(\mathrm{I}){ }^{j \mathrm{Pr}} \mathrm{PNP}$, however, exhibits a high selectivity of ortho-to-fluorine and follows the undirected pathway which involving the steps: (i) $\mathrm{C}-\mathrm{H}$ oxidative addition, (ii) $\mathrm{C}-\mathrm{B}$ reductive elimination, (iii) $\mathrm{B}-\mathrm{B}$ oxidative addition, and (iv) $\mathrm{B}-\mathrm{H}$ reductive elimination. The preference for ortho-to-fluorine selectivity in $\mathrm{Co}(\mathrm{I}){ }^{\mathrm{iPr}} \mathrm{PNP}$ catalyzed borylation is attributable to the acidity of ortho-to-fluorine $\mathrm{C}-\mathrm{H}$ bond, while in the silyl-directed pathway, the high steric hindrance in the transition state of $\mathrm{C}-\mathrm{B}$ reductive elimination leads to too high overall barrier to overcome. These calculation results well explain the experimental observation reported previously, strongly suggesting the accuracy of our calculation. The work present here therefore provides rational mechanistic insights into the origin of regioselective borylation of hydrosilyl substituted fluoroarenes. This will be helpful to well understand the underlying physics of the regioselective borylation of hydrosilyl substituted fluoroarenes and can be extended to the synthesis of other organic compounds with predictable regioselectivity by introducing suitable directing group, adjusting the available coordination sites on the catalyst, and/or modifying the electronic effects of the catalyst.

\section{Computational section}

Geometry optimizations without symmetry restriction were carried out at the $\mathrm{B}^{2} \mathrm{LYP}^{17} / \mathrm{BSI}$ level, where BSI denotes the combination of the lanl $2 \mathrm{dz}^{18}$ for Ir and Co, $6-31 \mathrm{G}(\mathrm{d})^{19}$ basis for other atoms. Frequency results were examined to confirm stationary points as transition states (only one imaginary frequency) or minima (no imaginary frequencies), and were also used to obtain zero-point energy-corrected enthalpies and free energies at $298.15 \mathrm{~K}$ and $1 \mathrm{~atm}$. In addition, intrinsic reaction coordinate (IRC) analysis was conducted to confirm that the transition state connects the correct reactant and product on the potential energy surface..$^{20}$ The energetic results were further improved by single-point energy calculations at $\omega \mathrm{B} \mathrm{XXD}^{21 a} / \mathrm{BSII}$ level of theory, where BSII represents a basis set with $\mathrm{SDD}^{22}$ for Ir and Co and Def2TZVP ${ }^{21 b}$ basis set for other atoms. The solvent effects accounted by the $\mathrm{SMD}^{23}$ solvation model, using the experimental solvent tetrahydrofuran. Furthermore, natural population analysis (NPA) ${ }^{24}$ was performed at the same level by single point calculations. The Gibbs free energies obtained from the $\omega \mathrm{B} 97 \mathrm{XD} / \mathrm{BSII} / \mathrm{B} 3 \mathrm{LYP} / \mathrm{BS} 1$ level was discussed in this 
study, unless otherwise specified. All calculations are performed with the Gaussian 09 program package. ${ }^{25}$

\section{Conflicts of interest}

There are no conflicts to declare.

\section{Acknowledgements}

We thank the Funding for Youth from Guangzhou University. We are grateful for the helpful suggestion from Prof. Hui Gao at Guangzhou Medical University.

\section{References}

1 (a) D. Aguilar, L. Cuesta, S. Nieto, E. Serrano and E. P. Urriolabeitia, Curr. Org. Chem., 2011, 15, 3441-3464; (b) L. Xu, G. H. Wang, S. Zhang, H. Wang, L. H. Wang, L. Liu, J. Jiao and P. F. Li, Tetrahedron, 2017, 73, 71237157; (c) Z. Y. He, Y. Hu, C. G. Xia and C. Liu, Org. Biomol. Chem., 2019, 17, 6099-6113; (d) L. Kuehn, M. M. Huang, U. Radius and T. B. Marder, Org. Biomol. Chem., 2019, 17, 6601-6606; (e) Y. H. Liu, Z. J. Jiang and J. P. Chen, Org. Biomol. Chem., 2020, DOI: 10.1039/D0OB00628A.

2 (a) J. V. Obligacion, S. P. Semproni and P. J. Chirik, J. Am. Chem. Soc., 2014, 136, 4133-4136; (b) T. Furukawa, M. Tobisu and N. Chatani, Chem. Commun., 2015, 51, 6508-6511; (c) H. Zhang, S. Hagihara and K. Itami, Chem. Lett., 2015, 44, 779-781; (d) T. Dombray, C. G. Werncke, S. Jiang, M. Grellier, L. Vendier, S. Bontemps, J. B. Sortais, S. Sabo-Etienne and C. Darcel, J. Am. Chem. Soc., 2015, 137, 4062-4065; (e) J. F. Hartwig, Chem. Soc. Rev., 2011, 40, 1992-2002; $(f)$ C. Xue, Y. Luo, H. L. Teng, Y. L. Ma, M. Nishiura and Z. M. Hou, ACS Catal., 2018, 8, 50175022; $(g)$ C. R. K. Jayasundara, D. Sabasovs, R. J. Staples, J. Oppenheimer, M. R. Smith III and R. E. Maleczka Jr, Organometallics, 2018, 37, 1567-1574.

3 Sterically controlled selective borylation was reported, see:(a) T. Ishiyama, J. Takagi, K. Ishida, N. Miyaura, N. R. Anastasi and J. F. Hartwig, J. Am. Chem. Soc., 2002, 124, 390-391; (b) S. Paul, G. A. Chotana, D. Holmes, R. C. Reichle, R. E. Maleczka, Jr and M. R. Smith III, J. Am. Chem. Soc., 2006, 128, 15552-15553; (c) I. A. I. Mkhalid, D. N. Coventry, D. Albesa-Jove, A. S. Batsanov, J. A. K. Howard, R. N. Perutz and T. B. Marder, Angew. Chem., 2006, 118, 503-505; Angew. Chem., Int. Ed., 2006, 45, 489-491; (d) M. A. Larsen and J. F. Hartwig, J. Am. Chem. Soc., 2014, 136, 4287-4299; (e) Y. Saito, Y. Segawa and K. Itami, J. Am. Chem. Soc., 2015, 137, 5193-5198. Directed selective borylation was reported, see: $(f)$ Y. Kuninobu, H. Ida, M. Nishi and M. Kanai, Nat. Chem., 2015, 7, 712-717; (g) L. Liu, G. H. Wang, J. Jiao and P. F. Li, Org. Lett., 2017, 19, 61326135; (h) J. Thongpaen, T. E. Schmid, L. Toupet, V. Dorcet, M. Mauduit and O. Baslé, Chem. Commun., 2018, 54, 82028205; (i) S. I. Kallane and T. Braun, Angew. Chem., Int. Ed., 2014, 53, 9311-9315; (j) For selected examples: E. C. Keske, B. D. Moore, O. V. Zenkina, R. Wang, G. Schatte and
C. M. Crudden, Chem. Commun., 2014, 50, 9883-9886; For reviews:; $(k)$ A. Ros, R. Fernandez and J. M. Lassaletta, Chem. Soc. Rev., 2014, 43, 3229-3243; (l) H. L. Ren, Y. P. Zhou, Y. P. Bai, C. M. Cui and M. Driess, Chem.-Eur. J., 2017, 23, 5663-5667.

4 D. W. Robbins and J. F. Hartwig, Org. Lett., 2012, 14, 42664269.

5 (a) W. K. Hagmann, J. Med. Chem., 2008, 51, 4359-4369; (b) P. Jeschke, ChemBioChem, 2004, 5, 570-589.

6 T. Furukawa, M. Tobisu and N. Chatani, J. Am. Chem. Soc., 2015, 137, 12211-12214.

7 J. Takaya, S. Ito, H. Nomoto, N. Saito, N. Kirai and N. Iwasawa, Chem. Commun., 2015, 51, 17662-17665.

8 A. J. Roering, L. V. A. Hale, P. A. Squier, M. A. Ringgold, E. R. Wiederspan and T. B. Clark, Org. Lett., 2012, 14, 3558-3561.

9 (a) C. Patel, V. Abraham and R. B. Sunoj, Organometallics, 2017, 36, 151-158; (b) L. Zhang and D. C. Fang, J. Org. Chem., 2016, 81, 7400-7410.

10 T. A. Boebel and J. F. Hartwig, J. Am. Chem. Soc., 2008, 130, 7534-7535.

11 J. V. Obligacion, M. J. Bezdek and P. J. Chirik, J. Am. Chem. Soc., 2017, 139, 2825-2832.

12 (a) C. Patel, V. Abraham and R. B. Sunoj, Organometallics, 2017, 36, 151-158; (b) L. Zhu, X. T. Qi, Y. Z. Li, M. Duan, L. F. Zou, R. P. Bai and Y. Lan, Organometallics, 2017, 36, 2107-2115; (c) J. Zhou, C. I. Lee and O. V. Ozerov, ACS Catal., 2018, 8, 536-545; (d) Y. H. Liu, J. P. Chen, K. S. Zhan, Y. Q. Shen, H. Gao and L. M. Yao, RSC Adv., 2018, 8, 35453-35460.

13 (a) J. V. Obligacion and P. J. Chirik, ACS Catal., 2017, 7, 43664371; (b) J. V. Obligacion, H. Y. Zhong and P. J. Chirik, Isr. J. Chem., 2017, 57, 1032-1036; (c) H. X. Li, J. V. Obligacion, P. J. Chirik and M. B. Hall, ACS Catal., 2018, 8, 1060610618; (d) T. M. Boller, J. M. Murphy, M. Hapke, T. Ishiyama, N. Miyaura and J. F. Hartwig, J. Am. Chem. Soc., 2005, 127, 14263-14278; (e) H. Tamura, H. Yamazaki, H. Sato and S. Sakaki, J. Am. Chem. Soc., 2003, 125, 1611416126; (f) G. P. Huang, M. Kalek, R. Z. Liao and F. Himo, Chem. Sci., 2015, 6, 1735-1746; $(g)$ T. P. Pabst, J. V. Obligacion, É. Rochette, I. Pappas and P. J. Chirik, J. Am. Chem. Soc., 2019, 141, 15378-15389.

14 E. E. Glendening, A. E. Reed, J. E. Carpenter, F. Weinhold, NBO (Natural Bond Orbital) 3.0, as implemented in GAUSSIAN 03, Gaussian Inc., Pittsburgh, PA, 2004.

15 Q. Li, C. W. Liskey and J. F. Hartwig, J. Am. Chem. Soc., 2014, 136, 8755-8765.

16 P. C. Roosen, V. A. Kallepalli, B. Chattopadhyay, D. A. Singleton, R. E. Maleczka Jr and M. R. Smith III, J. Am. Chem. Soc., 2012, 134, 11350-11353.

17 (a) C. Lee, W. Yang and R. G. Parr, Phys. Rev. B, 1988, 37, 785789; (b) A. D. Becke, J. Chem. Phys., 1993, 98, 5648-5652.

18 P. J. Hay and W. R. Wadt, J. Chem. Phys., 1985, 82, 270-283. 19 (a) P. C. Hariharan and J. A. Pople, Theor. Chem. Acc., 1973, 28, 213-222; (b) M. J. Frisch, J. A. Pople and J. S. Binkley, J. Chem. Phys., 1984, 80, 3265-3269. 
20 (a) K. Fukui, Acc. Chem. Res., 1981, 14, 363-368; (b) C. Gonzalez and H. B. Schlegel, J. Chem. Phys., 1989, 90, 2154-2161.

21 (a) J.-D. Chai and M. Head-Gordon, Phys. Chem. Chem. Phys., 2008, 10, 6615-6620; (b) F. Weigend and R. Ahlrichs, Phys. Chem. Chem. Phys., 2005, 7, 3297-3305.

22 M. Dolg, U. Wedig, H. Stoll and H. Preuss, J. Chem. Phys., 1987, 86, 866-872.

23 A. V. Marenich, C. J. Cramer and D. G. Truhlar, J. Phys. Chem. $B, 2009,113,6378-6396$.

24 (a) A. E. Reed, R. B. Weinstock and F. Weinhold, J. Chem. Phys., 1985, 83, 735-746; (b) A. E. Reed and F. J. Weinhold, Chem. Phys., 1985, 83, 1736-1740; (c) A. E. Reed, L. A. Curtis and F. Weinhold, Chem. Rev., 1988, 88, 899-926.

25 M. J. Frisch, G. W. Trucks, H. B. Schlegel, G. E. Scuseria, M. A. Robb, J. R. Cheeseman, G. Scalmani, V. Barone,
B. Mennucci, G. A. Petersson, H. Nakatsuji, M. Caricato, X. Li, H. P. Hratchian, A. F. Izmaylov, J. Bloino, G. Zheng,J. L. Sonnenberg, M. Hada, M. Ehara, K. Toyota, R. Fukuda, J. Hasegawa, M. Ishida, T. Nakajima, Y. Honda, O. Kitao,H. Nakai, T. Vreven, J. A. Montgomery Jr, J. E. Peralta, F. Ogliaro, M. Bearpark, J. J. Heyd, E. Brothers, K. N. Kudin, V. N. Staroverov, R. Kobayashi, J. Normand, K. Raghavachari, A. Rendell, J. C. Burant, S. S. Iyengar, J. Tomasi, M. Cossi, N. Rega, J. M. Millam, M. Klene, J. E. Knox,J. B. Cross, V. Bakken, C. Adamo, J. Jaramillo, R. Gomperts, R. E. Stratmann, O. Yazyev, A. J. Austin, R. Cammi, C. Pomelli, J. W. Ochterski, R. L. Martin, K. Morokuma, V. G. Zakrzewski, G. A. Voth, P. Salvador, J. J. Dannenberg, S. Dapprich, A. D. Daniels, Ö. Farkas, J. B. Foresman, J. V. Ortiz, J. Cioslowski and D. J. Fox, Gaussian 09, Gaussian, Inc., Wallingford CT, 2009. 